\title{
A PROVOCAÇÃO POÉTICA DOS ELEMENTOS MATERIAIS: NOVAS CATEGORIAS DE ANÁLISE NA ABORDAGEM SÓCIO-POÉTICA
}

\author{
THE POETICAL MOTIVATION OF THE MATERIAL ELEMENTS: NEW \\ CATEGORIES OF ANALYSIS IN THE SOCIAL-POETICAL APPROACH
}

\author{
LA PROVOCACIÓN POÉTICA DE LOS ELEMENTOS MATERIALES: \\ NUEVAS CATEGORIAAS DE ANÁLISIS EN EL ENFOQUE \\ SOCIO-POÉTICO
}

\begin{abstract}
RESUMO: Gauthier, Santos (1996) descrevem a sócio-poética como uma abordagem no conhecimento do ser humano e da sociedade, um caminho para a produção do conhecimento, que por meio de práticas diferenciadas de pesquisa e do educar mutual transforma poeticamente o saber para melhor conhecer. Os idealizadores da sócio-poética utilizam os lugares sócio-miticos, como categorias de produção e análise dos dados. Mas estimulam aqueles que trabalham com esta abordagem, a criarem novas técnicas e vivências, que facilitem a produção de dados no grupo pesquisador. Atendendo a este desafio e inspiradas no conceito de Imaginação Material de Gaston Bachelard, na Técnica da Imaginaçăo Ativa de C.G.Jung e nos experimentos de crescimento da gestalt-terapia de John Stevens, criamos novas técnicas e categorias de estudo na abordagem sócio-poética denominando-as de Técnica dos Elementos Materiais. Como os primeiros filósofos gregos, acreditamos que muito das imagens que produzimos provêm da provocação dos 4 elementos materiais (água, terra, fogo e ar). A pesquisa foi desenvolvida com diferentes grupos de enfermeiras, professoras de enfermagem, pós-graduandas em enfermagem e equipe de enfermagem de um hospital psiquiátrico. Evidenciou-se que a Técnica dos Elementos Materiais favorece a expressão de conteúdos inconscientes ou silenciados que interferem no cuidado de enfermagem, possibilitando à enfermeira explorar criativamente a si mesma, para inovar sua prática profissional.
\end{abstract}

PALAVRAS-CHAVE: imaginação, cuidado, criação.

INTRODUÇĀO

Neste trabalho buscou-se desenvolver a partir do método sócio-poético, técnicas de pesquisa que favorecessem a expressăo da criatividade do grupo pesquisador. A proposta fundamenta-se no conceito de Imaginaçăo Material de Gaston Bachelard, na Técnica de Imaginaçăo Ativa de C.G. Jung e nos experimentos de crescimento da gestalt-terapia de John Stevens.

O estudo tem por objetivo discutir os elementos materiais como categorias de produçăo e análise de dados, lançando os fundamentos para implementação de novas técnicas vivenciais que possibilitem estudos sócio-poéticos.

Gauthier (1995) destaca que a sócio-poética partilha com outras abordagens qualitativas, cinco

'Prof. Escola de Enfermagem da UFF, doutoranda em enfermagem.

2 Prof. Escola de Enfermagem da UFF, doutora em enfermagem. 
recusas básica na produção do conhecimento: 1) Cortar a cabeça do resto do corpo, sobretudo da sensualidade e da sensibilidade; 2) Năo dialogar com as culturas dominadas da sociedade; 3) Considerar o grupo focalizado como um objeto; 4) Separar a ciência da arte; 5) Separar o conhecimento da espiritualidade.

Com base dessas recusas Gauthier; Santos (1996) nomeiam como abordagem sóciopoética, toda prática social de produção do conhecimento que afirma: a importância do corpo na construçăo do imaginário, base das abstraçőes; a importância das culturas dominadas, das categorias de análises e conceitos que elas produzem; o papel da criatividade de tipo artístico na construçăo do conhecimento; o papel dos sujeitos pesquisados como co-responsáveis pelos conhecimentos produzidos; a importância do sentido espiritual, humano, das formas e dos conteúdos do saber.

Compreendemos a sócio-poética como uma abordagem metodológica complexa e multirreferencial no conhecimento do ser humano. Um método que exige do pesquisador uma atitude atenta, mas também devaniante; critica, mas sobretudo sensivel-intuitiva no processo da pesquisa.

Nesse estudo a imaginação criativa é tomada como a base do conhecimento que recebe a provocaçăo poética dos 4 elementos materiais (água, terra, fogo e ar).

Para criaçăo das novas categorias de análise, nos baseamos nos estudos de Bachelard sobre a imaginaçăo material. Ele descreve que os elementos materiais revelam nossas forças imaginantes, recebem nossos sonhos, tonificam nossa vontade. Destaca que ao estudarmos as imagens materiais, descobrimos a imago da nossa energia, pois a matéria é nosso espelho energético; é um espelho que focaliza as nossas potências iluminando-as com alegrias imaginárias. (Bachelard, 1991, p. 20)

\section{A IMAGINAÇÃO COMO ESPAÇO DE CRIAÇÃO}

A palavra imaginaçăo deriva do latim imaginatione, phantasia, e quer dizer fantasiar, criar. (Abbagnano, 1970)

Imaginar é a faculdade de representar imagens, de criar mediante a combinação de idéias, e ainda, criaçăo, invenção, fantasia. (Ferreira, 1986).

Kast (1997), descreve a imaginaçăo como espaço de liberdade, como condiçăo prévia para transformaçōes e manifestações criativas. Mas também como espaço de medo, medo de vivenciar experiências que nos conduzem para fora da realidade. Assim o mundo da imaginação, é um mundo de outras possibilidades que também se abrem para nós.

Segundo Bachelard (1990) e Ostrower (1993) a imaginação criativa vincula-se à especificidade de uma matéria, sendo uma imaginaçăo especifica em cada campo de trabalho. Diferenciando-se segundo uma certa materialidade, abrange possibilidade e impossibilidade. Săo essas delimitaçס̌es, que orientam o processo de criação, permitindo que se amplie as perspectivas e se atue em direçőes novas.

Definida em primeira instância por Aristóteles, o termo imaginaçăo assumiu o sentido de uma mudança gerada pela sensaçăo e semelhança a ela porquanto năo ligada a ela, uma condiçăo da inclinaçăo a qual tende exatamente a alguma coisa que não é presente e da qual năo se tem sensaçăo atual, conferindo à alma possibilidades várias, ativa ou passivas. (Abbagnano, 1970). Immanuel Kant, definiu a imaginação como poder mediador, meio sintético que organiza o caos da intuição sensória, de acordo com certas formas gerais imutáveis ou esquemas, distinguindo dois tipos de imaginaçăo: reprodutiva e transcendental. A imaginaçăo reprodutiva está sujeita à lei de associaçăo, sendo sua função solidificar, numa imagem, o caos de sensaçőes, brecá-lo, por meio da criaçăo de uma série ordenada, que a mente pode contemplar. A imaginaçăo transcendental tem funçăo construtiva, consiste em poder ativo espontâneo, um processo que se inicia por si mesmo, através de sua própria mediação interna, 
e não de uma causa externa. É anterior à experiência, năo subseqüente a ela. (Avens, 1993)

Face ao objetivismo do pensamento científico, a imaginaçăo manteve-se numa posição secundária em relação a outras esferas do saber, negando-se a ela qualquer valor noético, ou até mesmo tomando-a como fonte de erro. Sua penetraçăo foi assim restringida ao campo das artes.

No campo filosófico, mesmo Kant que vislumbrou os aspectos transcendentais da imaginaçăo, não destacou-!he uma posiçăo significativa como forma de saber.

A funçăo criadora da imaginaçăo foi principalmente evidenciada no Romantismo dos séculos XVIII e XIX. O romantismo rebelou-se contra o cógito cartesiano e contra o principio do eu penso kantiano, convertendo-se em um Self considerado primordial, ativo e não limitado pelo mundo objetivo.

A imaginação criativa foi descrita pelo romântico Coleridge citado por Avens (1993), não somente como a fonte da arte mas, também, como poder vivo e o agente de toda a percepçăo humana, capaz de dissolvê-la, torná-la difusa, de maneira a recriar e unificar. Ela é essencialmente vital, significando uma maneira de descobrir uma verdade mais profunda sobre o mundo.

Coube portanto ao Romantismo, sobre a influência do idealismo Kantiano, promover a imaginação à categoria de atividade criativa primária da mente humana ou do Self.

Atualmente existem vários conceitos a respeito da imaginação criativa. Neste estudo iremos nos valer daqueles descritos por Jung. Bachelard e Fayga Ostrower. Tomamos conhecimento a respeito do pensamento de Ostrower durante nossa formaçăo em arte-terapia e de Bachelard através do Curso Imagem e Criaçăo do Mestrado em Ciências da Arte da Universidade Federal Fluminense.

Do pensamento de Ostrower apreendemos que o homem elabora seu potencial criador através do trabalho. Esta autora rompe com uma visăo tradicionalista que atribui a um grupo seleto de sujeitos, "os artistas", a capacidade criativa. Desmistifica o caráter supérfluo, descomprometido da arte, referindo-a como engajamento de trabalho. Para ela a criaçăo se desdobra no trabalho e é ele que traz em si a necessidade que gera as possiveis soluções criativas. Para ser criativo no trabalho o homem não deve excluir do seu fazer o sensivel, a participaçăo interior, a possibilidade de escolha, de crescimento de transformação e conscientização espiritual. Define, portanto, a imaginaçăo criativa como um pensar especifico sobre um fazer concreto, que nasce do interesse, do entusiasmo de um individuo pelas possibilidades de certas matérias ou realidades.

Conquanto para ser criativa, a imaginaçăo necessita além de identificar-se com uma materialidade, contar com a visão global de um indivíduo, com a perspectiva que ele tenha do amplo fenômeno que é o humano. (Ostrower, 1993).

Já o pensamento de Bachelard nos impressionou por seu potencial transformador, reformador de idéias, gerador de sentimentos poéticos e de alegria.

Para Bachelard (1991), a imaginaçăo não é a faculdade de formar imagens, mas de deformá-las. Modificando as imagens fornecidas pela percepção, ela preocupa-se com a criaçăo, com a reforma cotidiana e năo com a reproduçăo da realidade. Ela năo se prende ao passado, e graças ao imaginário ela é essencialmente aberta, evasiva, é a própria experiência da novidade. A imaginaçăo é antes de tudo mobilidade.

Bachelard (1989) distingue duas linhas diferentes na qual a imaginaçăo se desenvolve. A primeira encontra seu impulso na novidade, no pitoresco, na variedade, nos acontecimentos inesperados, denominando-as de imaginaçăo formal. A segunda no fundo do ser, no primitivo e eterno, na substância, denominando-a imaginação material. Evidentemente estas duas forças imaginantes năo se excluem, elas muitas vezes atuam juntas.

Os estudos psicológicos sobre a imaginação privilegiam a imaginação formal. Bachelard contudo dedica-se ao estudo da imaginaçăo material. Ele a descreve como imagem direta da matéria, afastadas das formas superficiais. Elas possuem uma profundidade, uma intimidade, 
uma substancialidade, săo germinais, ou seja, já em sua manifestaçăo primitiva trazem consigo toda a sua potência. Possuem a condiçăo de nos revelar as nossas forças criativas imaginantes. Busca-se na energia material, elementos para materializar o imaginário. Para ele as imagens têm vida em si mesmas e nós nos recriamos no recíproco conflito de nossa consciência com a matéria. Destaca que a cada elemento material se associam diferentes tipos de devaneio, de estética, de psicologia ou mesmo de moral.

Em sua metodologia para o estudo das imagens poéticas, ele recomenda sentir a sua repercussão poética, apreendendo sua sonoridade e invasão em nosso ser. Ressalta que para isso é preciso afastarmos as ressonâncias sentimentais, que nos dispersam do plano poético. $\mathrm{E}$ também o hábito psicológico de descrever e interpretar incessantemente os sentimentos.

Bachelard (1992), descreve que o compromisso fundamental da imagem poética é com a alma e não com o saber. Ela visa diminuir tensర̋es, aliviar paixões, movimentar o ser, inaugurando continuamente novas formas, que são sempre variáveis.

$\mathrm{Na}$ década de 20, C.G. Jung começou a usar a linguagem expressiva ou artística como parte do tratamento psicoterápico. Jung entende que o imaginário năo é uma ficção, ou uma ilusão; ele é a faculdade de criar mediante a combinação de idéias, ele é simbólico, inconsciente e coletivo.

O inconsciente coletivo é constituído de imagem primordial, denominado arquétipo ${ }^{3}$, que reaparece no decorrer da história, sempre que a imaginação criativa for livremente expressa. As imagens năo escondem um sentido latente ou essencial além do seu estado aparente. No nivel imaginal, năo procuramos por mistérios ulteriores ou velados, ou campos imutáveis para a experiência humana. A verdade e a realidade da imagem são criadas e existem naquilo que é criado na imagem em si (Jung, 1985).

É precisamente por esta razăo que não há nenhuma necessidade de explicar as imagens da psique reduzindo seu conteúdo manifesto a algo inferior ou mais básico, sendo esse reducionismo interpretativo sinal de falta de imaginaçăo.

Jung descreve que as imagens săo anteriores ao mundo dos símbolos pois, no princípio, está a poesis ${ }^{4}$. Assim só podemos chegar ao antologicamente humano, o nada do centro do nosso ser, movimentando-nos pelo modo poético e usando instrumentos poéticos. Pois somente o poeta em nós, está afinado com nossa condição de nada essencial.

Avens (1993) adverte, que por detrás do empirismo cientifico, existe um mundo de realidade primordial independente - o mundo imaginal. As imagens são os dados básicos de toda a vida psiquica e o modo privilegiado de acesso ao conhecimento da alma.

Para Jung (1985) como para Bachelard (1994) a imaginaçăo é subjacente a todos os processos perceptuais e cognitivos, tudo que conhecemos é transmitido através de imagens. Assim somente sob a forma de imagens a libido ${ }^{5}$ poderá ser apreendida viva, e năo esfiapada pelo repuxamento das tentativas de interpretações racionais. Pois a imagem também não é só um produto da recepçăo do real, ela é idêntica a sua significaçãa. Ele năo procura nelas elementos disfarçados, relativos às vivências da infância dos individuos, como o fez Freud. Acredita que quando a imagem se configura sua significaçăo torna-se clara, ligadas aos arquétipos elas

${ }^{3}$ Arquétipo é um termo definido por Jung como uma marca-impressão, um agrupamento definido de caracteres arcaicos, que, em forma e significado, encerra motivos mitológicos, os quais surgem em forma pura nos contos de fada, nos mitos, nas lendas e no folclore.

- Criação da alma através da imaginação e da metáfora (Avens, 1993).

5 Libido ou energia psiquica é a intensidade do processo psiquico, seu valor psicológico. Libido é apetite, instinto permanente de vida que se manifesta pela fome, sede, sexualidade, agressividade, necessidades e os mais diversos interesses. Acrescenta que todos os fenômenos psiquicos são de natureza energética. Os complexos são nós de energia, os arquétipos são núcleos de energia em estado virtual, os símbolos sảo máquinas transformadas em energia. (Jung. 1985). 
retratam sua própria significação.

Ele defende a idéia de que o homem é basicamente criador de imagens, nossa existência é imaginação. Nossa imaginação é ativa, cheia de propósitos criadores.

Entre os principais métodos utilizados por Jung destacam-se: escutar os sonhos, amplificar e associar através da imaginação ativa, comparar as histórias das religiőes. Neste estudo iremos utilizar prioritariamente o método da imaginação ativa.

O conceito de Imaginaçăo Ativa segundo Jung (1985) compreende todas as formas de realização do símbolo, seja uma simples continuação visual do símbolo na imaginação, seja, de modo mais representativo, por meio de uma expressão artística. Do ponto de vista prático, ele descreve que esta pode começar de um sonho ou de uma impressão de natureza hipnagógica. A imaginação ativa é cheia de acontecimentos simbólicos se desenvolvem de acordo com uma lógica que Ihes é particular. Os passos metodológicos para o trabalho com a imaginação ativa são os seguintes:

1. Começa-se pela concentração num ponto de partida, que pode ser um objeto, uma paisagem, uma lembrança, etc.

2. Posteriormente o quadro mental vai ganhando movimento, a imagem se enriquece de detalhes, se dinamiza, se desenvolve. Aconselha-se neste momento não interromper o fluxo natural dos acontecimentos com racionalizações conscientes, assim o inconsciente produzirá uma série de imagens que farão uma história completa.

3. Expressa-se por meio de símbolos ou através de uma técnica artística (pintura, modelagem, tecelagem, costura, dança...) o material imaginado.

4. Finaliza-se estabelecendo comparações com outras idéias, sonhos, realidades culturais, sentidos simbólicos ou poéticos.

Esta última fase do método da imaginação ativa é também reconhecida como método de amplificação da consciência. No qual o sujeito toma consciência das mais diversas possibilidades de sentidos do conteúdo elaborado em sua imaginação, adquirindo a compreensão necessária de suas imagens arquetipicas.

\section{OS ELEMENTOS MATERIAIS COMO CATEGORIAS DE PRODUÇÃO E ANÁLISE DE DADOS}

Gauthier (1994) inspirado pelas imagens presentes nas culturas indigenas do Pacifico, criou a Vivência dos Lugares Sócio-míticos para trabalhar com o imaginário do grupo pesquisador. Ele observou que naquelas culturas se pensa em termos de lugares sócio-míticos. A projeçăo da lógica dessas imagens, designada pelas imagens da terra, poço, ponte, falha, fluxos, cume, túnel, labirinto, gruta, caminho, estrada, galáxia, rio, trilho e arco-íris, sobre as nossas histórias de vida, permite formalizar outros conteúdos além daqueles habitualmente construidos nas pesquisas, funcionando como um revelador de conteúdos freqüentemente silenciados no processo da pesquisa.

Tive a oportunidade de vivenciar a dinâmica dos lugares sócio-míticos, como membro do grupo pesquisador, por ocasiăo da fase de produçăo de dados da tese da Dra. Iraci Santos, e como facilitadora da pesquisa sobre o imaginário da loucura, coordenada pelo professor Gauthier, no Instituto Philipe Pinel/RJ.

Tais experiências mostraram-me a força criadora do nosso imaginário e o poder revelador, catalisador da utilização dos lugares sócio-míticos como categorias de produção e análise dos dados. Mas, tanto na fase de produção quanto de análise dos dados, observei que a vivência no processo de pesquisa de todos os lugares sócio-míticos, torna o estudo deveras extenso, dificultando o processo de conclusão da pesquisa.

Desse modo como pesquisadora em fase preliminar de elaboração de tese de doutorado, comecei a imaginar novas categorias de análise. Os critérios pensados inicialmente foram os seguintes: 
- As categorias deveriam ser tanto abrangentes quanto sucintas afim de facilitar o desenvolvimento e discussão da pesquisa por todo o grupo pesquisador.

- Deveriam possibilitar a expressão dos principios metodológicos da sócio-poética.

- Ter o poder revelador e catalisador de idéias.

- Facilitar o movimento e a expressão do imaginário.

- Estar ligado ao imaginário coletivo.

- Promover o relaxamento dinâmico do grupo pesquisador.

- Viabilizar a expressão poética do grupo-pesquisador.

Como admiradora da psicologia junguiana, iniciei minha investigação das possiveis categorias pelo estudo do princípio da quadrinidade de Jung. Todo o sistema de pensamento junguiano está fundado sobre a importância que ele dá ao número quatro. Para Jung (1985) a quaternidade representa o fundamento arquétipo da psique humana, a totalidade dos processos psiquicos conscientes e inconscientes. A análise que faz dos tipos psicológicos fundamentase nas 4 funçőes da consciência: o pensamento, o sentimento, a intuição ea sensação. Porntanto uma primeira pista para definição das novas categorias era que elas fossem definidas em número de quatro. Nesse período procurei fazer alguns cursos na área da arte, afim de adquirir conhecimentos sobre a aplicação de recursos, técnicas e fundamentos artísticos em minha tese.

Realizei por conta disso, um curso de arte-terapia onde tive a oportunidade de conhecer algumas técnicas e fundamentos de expressão artística. Mas como a ênfase do curso residia mais no uso do talento do que da técnica ou teoria da arte propriamente dita, fiquei de certa forma insatisfeita.

Assim fui procurar no Programa de Pós-Graduação em Ciências da Arte da UFF, um curso que ajudasse a aprofundar conhecimentos na área da arte. Matriculei-me no Curso Imagem e Criação, onde tomei conhecimento da face poética da obra de Gaston Bachelard. Até aquele momento só conhecia o aspecto filosófico de sua obra.

Meu contato com o Bachelard noturno foi através da obra Água e os Sonhos. Dela pude apreender que os nossos sonhos vinculam-se aos elementos matérias e que emanam sob sua provocação. Bachelard estabelece nessa obra uma lei dos quatro elementos materiais, classificando as diversas imaginaçőes materiais conforme elas se associem ao fogo, ao ar, á água e à terra. Como os antigos filósofos gregos, ele acredita que toda poética deve receber componentes de essência material.

A partir dessas concepçőes comecei a pensar nos elementos materiais como categorias de pesquisa do imaginário. Compreendi que a cada um dos elementos se associa um tipo de devaneio, de crença, de ideal, de filosofia, de estética, de psicologia, de moral e de poética. Que os elementos materiais catalisam e revelam conteúdos inconfessos (inconscientes) e nos mostram resplandecentes. Que o devaneio provocado por um elemento faz compreender a vida do universo pela vida do nosso coração.

Os quatro elementos săo o fundamento daquilo que Bachelard (1990) chamou de Imaginaçăo Material, inspirado nas filosofias tradicionais e nas cosmologias antigas. Bachelard classificou as diversas imaginações materiais conforme elas se associam ao fogo, ao ar, à água e à terra. Assinalou que para que cada devaneio tenha prosseguimento é preciso que ele encontre sua matéria, é preciso que um elemento material lhe dê sua própria substância, sua própria regra, sua poética específica.

Bachelard (1990) considera os quatro elementos como os hormônios da imaginação, cada um deles aciona grupos de imagens que ajudam a assimilação intima do real.

O fogo é, segundo Bachelard (1994), o elemento da mudança, do pronto devir, da sexualidade, da penetraçăo, da purificaçăo, regeneraçăo, renascimento.

O fogo simboliza a paixăo (principalmente amor e cólera), simboliza o espírito e o conhecimento intuitivo, purificação alquimica (Chevalier, 1994). 
A água é, segundo Bachelard (1989), elemento mais feminino e mais uniforme que o fogo, elemento mais constante. Simbolizando as forças humanas mais escondidas, mais simples, mais simplificantes, menos participativa, mais intima. A água é o elemento transitório, vertiginoso, desmoronante, é o infinito horizontal.

O ar é, segundo Bachelard (1990), o convite à viagem, é imagem de evasăo, da flutuaçăo, da mobilidade, da altura, é o infinito vertical.

$\mathrm{O}$ ar é, como o fogo, um elemento ativo, masculino. Associado ao vento, ao sopro, representa o mundo sutil intermediário do céu e a terra. É um símbolo sensivel da vida invisivel, um móbil universal e um purificador. É o meio próprio da luz, do alçar vôo, do perfume, da cor, estando associado ao mundo do espirito, (Chevalier, 1994).

A terra, segundo Bachelard (1991), tem como primeira característica uma resistência, uma força.

A terra simboliza a substância universal, o caos primordial. É a matriz que concebe as fontes, os minerais, os metais. Ela sustenta enquanto o céu cobre. Simboliza a função maternal, a fecundidade, a regeneração. Simbolo do consciente e de sua situaçăo de conflito. Símbolo do desejo terrestre e de suas possibilidades de sublimaçăo e de perversăo, (Chevalier, 1994).

Os quatro elementos săo, assim, um alimento inesgotável para a imaginaçăo.

\section{TÉCNICAS PROPOSTAS COM OS ELEMENTOS MATERIAIS}

Com o objetivo de dar substância aos devaneios das enfermeiras psiquiátricas, foram criadas 4 vivências com os elementos materiais. Para cada elemento foi estabelecida uma vivência corporal e uma técnica artística que facilitasse a expressão das imagens.

A primeira dinâmica denominou-se Cantando com o Ar e teve como objetivo promover o relaxamento, facilitar o processo de imaginaçăo criativa através do elemento $\mathrm{Ar}$.

Ao som de uma música própria para relaxamento (Airy voices) o grupo foi orientado a formar um grande circulo, estando os participantes de olhos fechados. Estando todos de mãos dadas começam a se balançar suavemente. Sugeriu-se ao grupo que imaginasse um barbante flexivel no topo de suas cabeças, que delicadamente, os puxava para cima, de forma que a espinha se endireitasse e a barriga e o peito se abrissem. Os participantes foram orientados para năo se esforçarem nem enrijecerem o corpo, deixando-os balançar um pouco. Sugeriu-se ao grupo que centralizassem a atenção na respiraçăo e, que ao fazer isso, mantivesse mente apenas a palavra suavidade, deixando que a respiraçăo e o corpo se tornassem suaves. Sugeriuse ao grupo sentir o corpo deslocando do chăo, voando para o alto do qual observam o mundo. Sugeriu-se que um céu azul, e que cada um passeasse por entre as nuvens, sentindo o vento e o sol, posteriormente o entardecer e as constelaçø̌es da noite. Finalizando o grupo foi orientado a retornar lentamente, e que ainda de olhos fechados, imaginar-se felizes cuidando de um paciente psiquiátrico, de forma que contribuisse para a sua autonomia. Sugeriu-se aos participantes a deterem-se, sem racionalizar, nos detalhes da primeira imagem que lhe aparecesse, permitindo que sua imaginaçăo voasse em suas asas. Orientou-se ao grupo a só abrir os olhos após conseguir obter a sua cena.

Após o relaxamento o grupo iniciou a construçăo de uma mandala pintando com sopro através de canudo a sua experiência imaginante. Depois descreveu com detalhes em um papel, as imagens e as sensaçōes obtidas na vivência com o ar.

A segunda dinâmica denominou-se Sonhando com a Pureza da Água. A vivência teve por finalidade provocar a imaginação através do elemento água. Sob o som da música de relaxamento The Winter Song, o grupo foi orientado a deitar-se em círculo no chăo com os olhos fechados. Sugeriu-se aos participantes que imaginassem ser matéria inerte no fundo do mar pré-histórico, existindo água por todos os lados, às vezes correntes suaves, às vezes ondas bravias. Sugeriu-se ainda, que a medida que a vida se desenvolvesse, eles se 
transformassem em algum tipo de erva ou planta marinha. Ai percebessem que a água em que estăo imersos é iluminada pelos raios de sol. E o sol traz consigo a imagem de uma situação de cuidado. O grupo foi então orientado a deixar-se inundar pelas imagens generosas e cristalinas da água, enquanto permanecesse cuidando de um paciente e quando se sentisse satisfeito abrisse os olhos suavemente e continuasse a construir a sua mandala, expressando imagens provocadas pelo elemento água. Orientou-se o grupo umedecer a parte do papel que iria trabalhar e com o dedo ou pincel borrados de tinta plasmasse suas imagens. Posteriormente o grupo escreveu sobre sua experiência.

A terceira dinâmica denominada Aquecendo com a Chama da Vela, teve por objetivo provocar imagens a partir do elemento fogo. Sob o som da música Oxford Suite (Ed Alleyne Johnson) o grupo foi orientado a assumir uma posiçăo confortável, deitados no chăo em círculo com os pés para fora, de modo que as cabeças dos participantes se tocassem. Sugeriu-se ao grupo sentir-se um fogo começando a tremular, que suas chamas tomassem movimentos. Solicitou-se aos participantes que observassem em que parte do corpo a chama principiava e como elas cresciam expandindo-se no ar. Sugeriu-se também que coo fogo observassem o espaço a sua volta e se transportassem para uma situaçăo de cuidado. A medida que o grupo certificou-se da imagem abriu os olhos e continuou seu trabalho através da mandala. Orientouse o grupo a trabalhar com lápis cera queimado na chama de uma vela e posteriormente registrar por escrito essa experiência.

A Quarta dinâmica denominada A Terra que Recebe Nossos Sonhos e Tonifica a Nossa Vontade, teve por objetivo provocar imagens a partir do elemento terra. Para o relaxamento é utilizada a música African Winds. O grupo foi orientado a deitar-se no chão formando um circulo unido pelos pés. Sugeriu-se ao grupo que entrasse em contato com as sensaçōes e vontades do seu corpo, que imaginassem sua mão esquerda como um pequeno botão de flor que cresce muito lentamente se movendo em direção ao sol, que aos poucos abre as pétalas para a brisa e a chuva, e quando a energia se vai, começa a murchar para formar as sementes e, aos poucos, entra na terra com sua semente. Solicitou-se ao grupo que expresse com o seu corpo a posiçăo de uma semente e que percebesse que tipo de semente era. Posteriormente sugeriuse ao grupo ser primavera e que como flores comecem a brotar, movendo-se mande uma pequena raiz para baixo da terra e um pequeno ramo em direçăo ao sol. Sugeriu-se ao grupo que continuasse a crescer e que movendo-se tomasse consciência de como seu corpo se sentia, enquanto lentamente faziam esta semente crescer e se transformar em algum tipo de planta ou árvore e que deste modo se transportassem para uma situação de cuidado. Após ter obtido sua imagem os participantes foram orientados para a construçăo de sua mandala. Desta vez iriam trabalhar sua mandala com argila e depois escreveriam sobre esta experiência.

No momento seguinte realizou-se um painel de todo o material produzido. Cada participante apresentou sua mandala ao grupo, comentando em seguida sobre sua experiência com o processo de criaçăo imaginante. Discutimos a partir dai as possibilidades de aliança entre o cuidado de enfermagem e o projeto de autonomia/reabilitação do paciente psiquiátrico.

Finalizamos nosso encontro com um relaxamento final, tendo como fundo musical a canção Brincadeira de Roda, da cantora Elis Regina. Neste relaxamento o grupo formou duas rodas, estando uma dentro da outra, de modo que os participantes da roda de dentro olham para os da roda de fora. Enquanto a roda de dentro gira no sentido horário, a de fora gira no sentido anti-horário, de modo que todos os participantes possam se olhar durante alguns minutos. Ao desfazer as rodas cada participante se despede do outro, dizendo-lhe uma palavra de sua escolha. 


\title{
CONSIDERAÇÕES FINAIS
}

O grupo percebeu através das vivências com os elementos materiais, que há um espaço da imaginação em que a vida pulsa, caotiza-se e ordena-se. Assim a realidade apresenta-se de forma diversa para cada pessoa, possibilitando a criatividade de cada um.

Evidenciou-se que a Técnica dos Elementos Materiais favorece a expressão de conteúdos inconscientes ou silenciados que interferem no processo de pesquisa ajudando a enfermeira a explorar criativamente a si mesma, para inovar sua prática profissional.

A Técnica dos Elementos Materiais ajudou a romper com o processo de produção dominante de sentidos sobre o tema orientador da pesquisa e a diminuir a tensão na produção do conhecimento.

\begin{abstract}
Gauthier and Santos (1996) describes the socio-poetics as na approach of knowledge of human-being and society, a way for the production of knowledge by means of a variety of research practices and education that poetically transforms knowledge for better understanding. The creators of socio-poetics utilize as analysing categories the geo-mitic places, thus stimulating those who work with this approach to create new tecnics and life experiences in order to improve data production in the research group. Playing attention to this challenge and inspired in the concepts of Material Imagination Gaston Bachelard, C.G.Jung Active Imagination Tecnic and in the growth experiments of John Stevens's gestalt-therapy, we created the Tecnic of Material Elements, based in the images provoked by the 4 elements (water, earth fire and air). We concluded that this new tecnic favored the expression of inconnscious or silenced contents that interfere in nurse care, thus allowing nurses to explore themselves creativily and to improved their professional practcing.
\end{abstract}

KEYWORDS: imagination, care, creation.

RESUMEN: Gauthier; Santos (1996) describen la socio-poética como un enfoque en el conocimiento del ser humano y de la sociedad, un camino para la producción del conocimiento, y que mediante unas prácticas diferenciadas de investigación y del educar mutual transforma poéticamente el saber para mejor conocer. Los idealizadores de la socio-poética utilizan los lugares socio-miticos, como categorias de producción y análisis de datos. Pero, estimulan aquellos que trabajan con este enfoque, a criar nuevas técnicas y vivencias que faciliten la producción de datos en el grupo investigador. Atendiendo a este desafio e inspiradas en el concepto de Imaginación Material de Gaston Bachelard, en la Técnica de la Imaginación Activa de C. G. Jung y en los experimentos de crecimiento de la gestalt-terapia de John Stevens hemos creado nuevas técnicas y categorias de estudio en el enfoque socio-poético y las hemos denominado "Técnicas de los Elementos Materiales". Asi como los primeros filósofos griegos, creemos que muchas de las imágenes que producimos provienen de la provocación de los 4 elementos materiales (agua, tierra, aire y fuego). La investigación fue desarrollada com diferentes grupos de enfermeras, profesoras de enfermeria, posgraduadas em enfermeria y un equipo de enfermeria de un hospital psiquiátrico. Quedó evidenciado que la Técnica de los elementos Materiales favorece la expresión de contenidos inconscientes o silenciados que interfieren en el cuidado de enfermeria y le posibilita a la enfermera explorarse creativamente a si misma, para com ello innovar su práctica profesional.

PALABRAS CLAVE: imaginación, cuidado, creación 


\section{REFERÊNCIAS BIBLIOGRÁFICAS}

ABBAGNANO. Dicionánio de filosofia. Trad. Alfredo Bosi. São Paulo: Mestre Jou, 1982.

ACHERBERG. A imaginação na cura. São Paulo: Summus, 1996.

ALENCAR, Eunice. Criatividade. Brasilia: Ed. UNB, 1995.

AVENS, Roberts. Imaginação é realidade. Petrópolis: Vozes, 1993.

BACHELARD, Gaston. A água e os sonhos. São Paulo: Martins Fontes, 1989. . O ar e os sonhos. São Paulo: Martins Fontes, 1990. . A terra e os devaneios da vontade. São Paulo: Martins Fontes, 1991. A poética do espaço. São Paulo: Martins Fontes, 1992. A psicanálise do fogo. São Paulo: Martins Fontes, 1994.

CHEVALIER, J; GUEERBRANT, A. Dicionário de simbolos. Rio de Janeiro: José Olympio, 1994. FERREIRA, Aurélio. Dicionário de lingua portuguesa. 2. ed. Rio de Janeiro: Nova Fronteira, 1986.

GAUTHIER, Jacques. Innovations of contradictions de l'education populaire a Rio de Janeiro. SaintDennis: Escol, Université Paris 8, 1994. (Mimeogr.) . Para uma sócio-poética. 1995. (Mimeogr.)

GAUTHIER, Jacques; SANTOS, Iraci. $A$ sócio-poética. Rio de Janeiro: UERJ, DEPEXT, NAPE, 1996. JUNG, Carl G. fundamentos da psicologia analitica. 3. ed. Petrópolis: Vozes, 1985. . O espirito na arte e na ciência. Petrópolis: Vozes, 1988. . O homem e seus símbolos. Rio de Janeiro: Nova Fronteira, 1993.

KAST, Verena. A imaginação como espaço de liberdade - diálogos entre o ego e inconsciente. São Paulo: Ed. Loyola, 1997.

OSTROWER, Fayga. Criatividade e processo de criação. Petrópolis: Vozes, 1993. . Universo da arte. Rio de Janeiro: Campus, 1991.

STEVENS, John. Tomar-se presente: experimentos de crescimento em gestalt-terapia. São Paulo: Summus, 1988. 